\title{
Reduced Spine Density in Specific Regions of CA1 Pyramidal Neurons in Two Transgenic Mouse Models of Alzheimer's Disease
}

\author{
Claudia Perez-Cruz, ${ }^{1}$ Marc W. Nolte, ${ }^{1}$ Marcel M. van Gaalen, ${ }^{1}$ Nathan R. Rustay, ${ }^{2}$ Annelies Termont, ${ }^{3}$ An Tanghe, ${ }^{3}$ \\ Frank Kirchhoff, ${ }^{4,5}$ and Ulrich Ebert ${ }^{1}$ \\ ${ }^{1}$ Neuroscience Research, Global Pharmaceutical Research and Development (GPRD), Abbott, D-67061 Ludwigshafen, Germany, ${ }^{2}$ Neuroscience Research, \\ GPRD, Abbott Park, Illinois 60064, ${ }^{3}$ reMYND NV Bio-Incubator, B-3001 Leuven-Heverlee, Belgium, ${ }^{4}$ Max Planck Institute of Experimental Medicine, \\ D-37075 Göttingen, Germany, and 5 Department of Molecular Physiology, University of Saarland, D-66421 Homburg/Saar, Germany
}

One major hallmark of Alzheimer's disease $(\mathrm{AD})$ is the massive loss of synapses that occurs at an early clinical stage of the disease. In this study, we characterize alterations in spine density and the expression of synapse-associated immediate early gene Arc (activity-regulated cytoskeleton-associated protein) in the hippocampal CA1 regions of two different amyloid precursor protein (APP) transgenic mouse lines before plaque development and their connection to performance in hippocampus-dependent memory tests. The density of mushroom-type spines was reduced by $34 \%$ in the basal dendrites proximal to the soma of CA1 pyramidal neurons in 5.5-month-old $\operatorname{Tg} 2576$ mice, carrying the Swedish mutation, compared with wild-type littermates. A similar reduction of $42 \%$ was confirmed in the same region of 8-month-old APP/Lo mice, carrying the London mutation. In this strain, the reduction extended to the distal dendritic spines (28\%), although no differences were found in apical dendrites in either transgenic mouse line. Both transgenic mice lines presented a significant increase in Arc protein expression in CA1 compared with controls, suggesting rather an overactivity and increased spine turnover that was supported by a significant decrease in number of somatostatin-immunopositive inhibitory interneurons in the stratum oriens of CA1. Behaviorally, the transgenic mice showed decrease freezing in the fear contextual conditioning test and impairment in spatial memory assessed by Morris water maze test. These data indicate that cognitive impairment in APP transgenic mice is correlated with impairment of synaptic connectivity in hippocampal CA1, probably attributable to loss of inhibitory interneurons and subsequent hyperactivity.

\section{Introduction}

Alzheimer's disease $(\mathrm{AD})$ is an age-dependent neurodegenerative disorder that is characterized by a progressive cognitive decline and by several structural brain alterations, such as deposition of amyloid $\beta(\mathrm{A} \beta)$ peptides in parenchymal plaques and cerebral blood vessels, intraneuronal formation of neurofibrillar tangles, and loss of neuronal subpopulations (Terry et al., 1998). One major hallmark of AD is the massive loss of synapses that occurs at an early clinical stage of the disease (Masliah et al., 1991; Sze et al., 1997). Synaptic loss has been correlated with cognitive deficits in AD patients (DeKosky and Scheff, 1990; Terry et al., 1991; Lippa et al., 1992). Although a detailed morphological analysis of changes in synaptic connectivity in the $\mathrm{AD}$ brain over time is

Received Nov. 24, 2010; revised Jan. 10, 2011; accepted Jan. 13, 2011.

This work was supported by the Deutscher Akademischer Austausch Dienst and Consejo Nacional de Ciencia y Technología (C.P.-C. and F.K.). We are grateful to B. Janson, A.Stanek, B. Theobald, and C. Schuster for their excellent help in tissue processing, (immuno-)histochemical stainings, and microscopical analyses.

Correspondence should be addressed to Dr. Claudia Perez-Cruz, Neuroscience Research, Global Pharmaceutical Research and Development, Abbott, Knollstrasse, D-67061 Ludwigshafen, Germany. E-mail: cau9@yahoo.com and ulrichmebert@aol.com.

M. W. Nolte's present address: Department of Pharmacology and Toxicology, CSL Behring, D-35094 Marburg, Germany.

DOI:10.1523/JNEUROSCI.6142-10.2011

Copyright $\odot 2011$ the authors $\quad 0270-6474 / 11 / 313926-09 \$ 15.00 / 0$ difficult and limited to the use of postmortem material, the generation of amyloid precursor protein (APP) transgenic (Tg) mice that overproduce $A \beta$ has enabled a better understanding of the functional and morphological consequences of A $\beta$ overproduction.

Dendritic spines are anatomical specializations on neuronal cells forming distinct compartments that isolate input from different synapses and are essential for excitatory synaptic transmission (Bonhoeffer and Yuste, 2002). As postsynaptic dendritic contacts, decreases in spine numbers might correlate with the loss of afferent synaptic terminals (Parnavelas et al., 1974; Gould et al., 1990; Cheng et al., 1997). Several in vitro studies have demonstrated that oligomeric aggregates of $\mathrm{A} \beta$ cause a reduction in the number and/or length of dendritic spines in hippocampal neurons (Calabrese et al., 2007; Lacor et al., 2007; Shankar et al., 2007). However, a similar reduction of dendritic spine density in the CA1 region of the hippocampus by in vivo-generated $\mathrm{A} \beta$ oligomers, e.g., in young APP transgenic animals, has not been shown. The aim of this study was to evaluate the impact of $A \beta$ overexpression on the number of dendritic spines of CA1 pyramidal neurons in two transgenic APP mouse lines, before onset of plaque formation. The Swedish (Tg2576) and London (APP/Lo) mutations are recognized APP transgenic mouse models for pre- 
clinical and drug developmental studies (Hsiao et al., 1996; Moechars et al., 1999; Tanghe et al., 2010).

Although the spine density of pyramidal neurons was determined by the Golgi-Cox method (Gibb and Kolb, 1998), accompanying pathological effects were analyzed by staining the immediate-early gene product Arc (activity-regulated cytoskeletonassociated protein), also named Arg3.1 (activity-regulated gene of $3.1 \mathrm{~kb}$ ) as a marker for synaptic functional and morphological changes, somatostatin (SOM) immunohistochemistry as a marker of inhibitory interneuron integrity, and memory tests as a marker of functional consequences of synaptic changes in same individuals. This is the first study showing morphological alterations in spine density in specific dendritic regions of CA1 pyramidal neurons with possible consequences on spine turnover and inhibitory interneurons, and ultimately cognitive behavior, in two different APP transgenic mouse lines before onset of plaque formation. Presence of pathology at early age suggests that soluble oligomeric rather than deposited fibrillar $A \beta$ is responsible for these deficits.

\section{Materials and Methods}

Animals

Female Tg2576 mice (5.5 months old; Taconic Farms), APP/Lo mice (8 months old; bred in-house), and age-matched littermate wild-type control mice were housed individually in Macrolon type 2 cages under standard laboratory conditions, $21 \pm 1{ }^{\circ} \mathrm{C}$ air temperature, and $55 \pm 15 \%$ humidity, with access to food and water ad libitum. Experimental procedures were approved by Abbott's Animal Welfare Officer and were performed in accordance with the European and German national guidelines as well as recommendations and policies of the U.S. National Institutes of Health Principles of Laboratory Animal Care (1996 edition). All experiments were performed during the light phase of the $12 \mathrm{~h}$ day/ night cycle.

\section{Behavioral testing}

In house, we have validated the contextual fear conditioning test with Tg2576 mice, but for technical reasons, in APP/Lo mice, a modified Morris water maze has been proven to be most reliable (Moechars et al., 1999; Tangle et al., 2010). This strain selectivity for deficits in different tasks may be attributable to genetic background. Thus, we have applied a different test to each strain of mice as described below.

Tg2576 mice and contextual fear conditioning. Mice were placed into the conditioning box (Hamilton Kinder), and the computer program was started. Mice were given $2 \mathrm{~min}$ to explore the conditioning chamber and then presented with a tone $(70 \mathrm{~dB}, 15 \mathrm{~s})$. The tone stimulus coterminated with a footshock $(0.78 \mathrm{~mA}, 2 \mathrm{~s})$. This stimuli pairing was repeated two times, with presentations spaced 2 min apart. Thirty seconds after the second shock, the mice were removed from the chamber. Mice were returned to the home cage and colony room. Before the first mouse and between mice, the chambers were wiped clean with isopropyl alcohol and allowed to dry before testing.

Twenty-four hours later, mice were placed back into the conditioning chamber for a 5 min contextual conditioning test without tone or shock presentation, in which the mice were scored for the presence or absence of freezing (lack of movement except for respiration). Mice were removed from the chamber after the 5 min test, returned to the home cage, and moved to another test room for the novel context test. After $1 \mathrm{~h}$ of habituation, mice were placed into the novel context box that had several differences from that of the test chamber: the lighting was reduced, chambers were made of clear Plexiglas and were larger in size than the contextual conditioning chambers, and the floor of the chambers were smooth, white plastic that were coated lightly with a $1 \%$ vanilla extract solution (reapplied between mice). The computer program consisted of $3 \mathrm{~min}$ without any stimulus presentation, followed by $3 \mathrm{~min}$ of the tone stimulus. Mice were scored for the presence or absence of freezing in the first $3 \mathrm{~min}$ to examine differences in freezing to the novel context and for the $3 \mathrm{~min}$ of tone presentation to assess the memory for the tone previously paired with the footshock.
APP/Lo mice and water maze. A custom-made water pool $(100 \mathrm{~cm}$ diameter) with white, nontransparent walls was located in a well-lit room with a number of distal extramaze cues. The water $\left(25^{\circ} \mathrm{C}\right)$, which was made opaque with coffee creamer, was filled and drained daily up to $\sim 10$ $\mathrm{cm}$ from the top of the pool edge. A clear Plexiglas escape platform $(9 \mathrm{~cm}$ diameter) was located $0.5 \mathrm{~cm}$ below the water surface in the center of one of eight equally sized pool sectors $(\sim 20 \mathrm{~cm}$ from the edge of the platform to the pool wall). The platform location was selected randomly for each mouse but was kept constant for each individual mouse throughout training. For each trial, a mouse was released from any of eight start boxes (filled with water and separated from the pool by the manually operated sliding door) and had $60 \mathrm{~s}$ to locate the escape platform, in which it was allowed to remain for $10 \mathrm{~s}$. The mouse was then returned to its holding cage, which was located under an incandescent red heat lamp. If the platform was not found in the allotted time, the mouse was gently placed on the platform using an appropriately sized plastic spoon. The mice were given two trials per day for $8 \mathrm{~d}$. Four mice were trained successively in a group enabling intertrial intervals to be $5 \mathrm{~min}$. The mice were tracked in the pool by an Ethovision video tracking system (Noldus).

\section{Histological analysis}

After behavioral testing, animals were deeply anesthetized by intraperitoneal injection with a mixture of $50 \mathrm{mg} / \mathrm{ml}$ ketamine and $10 \mathrm{mg} / \mathrm{ml}$ xylazine $(200 \mu \mathrm{l} / 100 \mathrm{~g}$ body weight $)$ and with $0.1 \mathrm{mg} / \mathrm{ml}$ atropine and perfused transcardially with $0.1 \mathrm{M}$ PBS. Aware of the sensitivity and immediate effects of handling on the expression of Arc and spine formation/ elimination, we kept the time interval between behavioral testing and the time when the animals were killed between 60 and $90 \mathrm{~min}$ in all animals.

Golgi-Cox staining. Directly after perfusion, the right hemisphere was dissected out and processed for a modified Golgi-Cox staining as described by the manufacturer (Rapid Golgi; FD NeuroTechnologies). Coronal sections $(240 \mu \mathrm{m})$ were obtained using a freezing-sliding microtome (Frigomobil 1206; Reichert-Jung), mounted on 2\% gelatincoated glass slides, and stored in Golgi solution in the dark at room temperature. After 2 weeks, sections were rinsed, dehydrated, cleared of xylene, and mounted onto gelatinized glass slides. Slides were coverslipped and allowed to dry before quantitative analysis. Several pyramidal neurons impregnated with the Golgi solution were readily identified in the dorsal hippocampal region by their characteristic triangular soma shape and numerous dendritic spines (Robinson and Kolb, 1997). At least four neurons per animal were three-dimensionally reconstructed by NeuroLucida Software (MicroBrightField). For spine quantification, a $100 \times$ oil-immersion objective was used to identify mushroom-like spines in dendrites longer than $10 \mu \mathrm{m}$. Straight branches were preferred to have a clear presentation of mushroom-like spines. At least three proximal (30-120 $\mu \mathrm{m}$ from soma) and three distal (220-340 $\mu \mathrm{m}$ from soma) dendritic segments were quantified in each neuron (Fig. 1). Spine densities were calculated as mean numbers of spines per micrometer per dendrite per neuron in individual mice per group. Spines located on proximal dendrites and spines located on distal dendrites were analyzed separately.

Immunohistochemistry. After brain removal, the left hemisphere was immersion fixed in $4 \%$ formaldehyde in PBS for $\sim 24 \mathrm{~h}$ at $4^{\circ} \mathrm{C}$ with subsequent transfer in $30 \%$ sucrose/phosphate buffer for at least $3 \mathrm{~d}$. Thereafter, eight series of coronal sections were cut at $40 \mu \mathrm{m}$ on a freezing microtome. Accordingly, sections were stained slide mounted for detection of Arc protein levels or free floating for somatostatin-positive cells quantification. Residual series were kept frozen in cryoprotectant medium for long-term storage.

Activity-regulated cytoskeleton-associated protein (Arc). An automated staining system was used for Arc immunohistochemistry (Discovery; Roche Diagnostics). Briefly, after incubation for $30 \mathrm{~min}$ in $0.25 \% \mathrm{H}_{2} \mathrm{O}_{2} /$ methanol solution and washing steps with PBS, sections were mounted on SuperFrost Plus slides (Menzel Glaeser), air dried, and subsequently transferred into the automated staining system. For all stainings, the diaminobenzidine (DAB) technique was used for chromogenic reaction (DAB Map kit; Roche Diagnostics). Briefly, after a fixation step with $4 \%$ formaldehyde in PBS/reaction buffer for $12 \mathrm{~min}$, followed by a mild CC1 heat pretreatment (delivered from Roche Diagnostics), slides were incu- 
bated with primary antisera in antibody diluent (Roche Diagnostics) at room temperature for $6 \mathrm{~h}$. The Arc antibody was used at a dilution of 1:200 (applied concentration, C-7; Santa Cruz Biotechnology). Thereafter, slides were exposed to the matching biotinylated secondary antibody in antibody diluent (Roche Diagnostics) for $30 \mathrm{~min}$ at $37^{\circ} \mathrm{C}$. The secondary antibody was used at a dilution of 1:500 (applied concentration, donkey antimouse IgG; Jackson ImmunoResearch). All other steps (blocking steps, chromogenic DAB reaction, etc.), which are included in the $\mathrm{DAB}$ Map kit procedure, are standardized and controlled by the Discovery autostainer and cannot be influenced by the researcher. After finalization of automated staining, slides were washed in normal water, dehydrated in graded ethanols, cleared in XTRA-Solve (J. T. Baker), and coverslipped with UltraKitt (J. T. Baker). Samples with omission of primary antibody were included as negative controls in the same run and confirmed antibody specificity because in no case staining was seen. Furthermore, brain sections from various mice with known expression pattern were used as positive controls.

Somatostatin-positive cells. Free-floating coronal sections ( $40 \mu \mathrm{m}$ thick) from $\mathrm{Tg} 2576$ and wild-type mice were pretreated with $3 \% \mathrm{H}_{2} \mathrm{O}_{2} /$ methanol in $0.1 \mathrm{M}$ PBS, pH 7.4, for $30 \mathrm{~min}$ and with an avidin/biotin blocking kit (Vector Laboratories) for $30 \mathrm{~min}$. Sections were rinsed two times with Tris-buffered saline Tween (TBST) buffer and then blocked for endogenous secondary antibody with $5 \%$ normal goat-serum in TBST. Thereafter, sections were incubated with a polyclonal rabbit antibody against somatostatin (Santa Cruz Biotechnology) diluted $1: 1000$ in $1 \%$ normal goat-serum/TBST overnight at room temperature. Sections were rinsed and incubated for $30 \mathrm{~min}$ at room temperature in a 1:500 dilution anti-rabbit IgG (Vector Laboratories). Thereafter, sections were incubated with Vectastain ABC Reagent for 30 $\min$ (Vector Laboratories) at room temperature, and the DAB technique was used for chromogenic reaction. After finalization of staining, slides were washed in normal water, dehydrated in graded ethanol, cleared in XTRA-Solve (J. T. Baker), and coverslipped with UltraKitt (J. T. Baker). Samples with omission of primary antibody were included as negative controls.

Immunohistochemistry image analysis. For analysis, we used five to seven labeled sections per animal ( $40 \mu \mathrm{m}$ thick, $\sim 320 \mu \mathrm{m}$ apart, starting at approximately $-2.8 \mathrm{~mm}$ posterior to bregma) (Paxinos and Franklin, 2001). For Arc image analysis, sections were digitized to grayscale pictures using a Carl Zeiss Axioplan 2 microscope and analyzed for optical densities using Image-Pro Plus software (Media Cybernetics). For somatostain-positive cell analysis, manual quantification was done by using the Neurolucida System (MicroBrightField). Depending on the dimension of the analyzed region, specific a priori-designed and calibrated areas of interest were used for determination of optical densities or number of positive cells within a given region. CA1 dorsal hippocampal region was identified by anatomical hallmarks and according to standard mouse stereotaxic brain atlas (Paxinos and Franklin, 2001). A square area of $\sim 1.875 \mu \mathrm{m}^{2}$ (for both stratum pyramidale and stratum oriens of CA1) and $22.500 \mu \mathrm{m}^{2}$ (stratum radiatum of CA1) was used for analysis of Arc staining. At least two measurements of the optical density were obtained from each region within a given section and averaged. Background optical density values, obtained from coverslipped glass slides without sections, were determined and set to $100 \%$ transmission. Additionally, all data of Arc optical density measurements were corrected for tissue background staining by subtracting optical density values from fiber tracts within the same section, e.g., corpus callosum. For somatostatin-positive cell counting, a frame covering the whole surface area of each region of interest (mean values for CA1 stratum oriens, $381,625 \mu \mathrm{m}^{2}$; CA1 stratum lacunosum-moleculare, 299,812 $\mu \mathrm{m}^{2}$; dentate gyrus, 69,539 $\mu \mathrm{m}^{2}$ ) (Fig. 1) was marked. Then, the number of somatostatin-positive neurons was counted. An average of five to seven transverse sections ( $320 \mu \mathrm{m}$ apart) were measured in each animal. The CA1 dorsal hippocampal region was defined using a $2.5 \times$ objective, and the number of neurons was counted using a $40 \times / 1.3$ oil differential interference contrast objective following the description made by Vela et al. (2003). Briefly, cell density values were obtained by dividing the number of immunoreactive neurons by the total area of the corresponding hippocampal region of interest (see above). The density of immunolabeled neurons from different hippocampal regions was averaged and expressed as the mean number of positive cells per square millimeter. It was not our intention to determine the total immunostained cell number in the whole mouse hippocampus. We are aware that, if this was the aim, Cavalieri point count in combination with three-dimensional optical dissector methods would be more appropriate (Ramos et al., 2006). All analysis was performed by a scientist blinded to the genotype status of the animal. 
Statistical analysis

All data are presented as mean + SEM, and $p<0.05$ was considered statistically significant. Contextual conditioning data was assessed by unpaired $t$ test. For water maze data, measures of latency to find the platform were obtained for each trial and then averaged daily values were subjected to two-way ANOVA with repeated measures on time. Whenever applicable for repeated measures analysis, Mauchly's test of sphericity was applied and the degrees of freedom were corrected to more conservative values using the Huynh-Feldt's $\varepsilon$ for any terms involving factors in which the sphericity assumption was violated. Statistical analysis of the spine density was performed with the mean total number of spines per micrometer per neuron per mouse for each group, which were compared by unpaired $t$ test. For optical density (Arc) and cell count (somatostatin) analyses, an unpaired $t$ test was used.

\section{Results}

\section{Behavioral testing}

Contextual conditioning was assessed in Tg2576 mice by analyzing the time spent freezing in the conditioning context on the test day (day 2). Tg2576 mice spent significantly less time freezing than the wild-type controls $(t=4.023, \mathrm{df}=16 ; p<0.01)$ (Fig. $2 A)$. When tested in the novel context, wild-type and transgenic mice did not differ in the levels of non-associative freezing ( $p=$ 0.92 ) (Fig. 2A). The performance in the water maze was tested in APP/Lo mice. Over $7 \mathrm{~d}$ of training, mice improved their ability to find the submerged platform. During the last day of training, wild-type animals had shorter latencies to find the platform than those in APP/Lo mice (Fig. $2 \mathrm{~B}$ ) (genotype $\times$ time interaction, $\left.F_{(1,156)}=10.82, p<0.001\right)$.

\section{Density of synaptic spines in CA1 of the hippocampus}

To study the anatomical basis of the cognitive deficit in the hippocampus-based tests, synaptic connections were quantified by counting mushroom-like spines in the dendritic region of hippocampal CA1. A total of 18-20 pyramidal neurons in each wild-type and transgenic mice were included for final analysis ( $n \geq 6$ animals per group). All of the neurons resided in the dorsal part of the CA1 hippocampal region and were completely stained along basal and apical dendrites. Segregation analysis was done to differentiate basal from apical dendrites in the same neuron (Fig. 1). In Tg2576 mice, the spine density in basal dendrites proximal to soma were reduced by $34 \%$ compared with wild-type littermates $(t=4.68, \mathrm{df}=8 ; p<0.01)$. Basal dendrites distal to soma and apical dendrites both proximal and distal to the soma presented similar values between transgenic and control mouse (Fig. 3A).

In APP/Lo mice, the number of spines in basal dendrites proximal to soma were also reduced by $42 \%$ compared with wild-type littermates $(t=5.224, \mathrm{df}=9 ; p<0.001)$. In addition, these mice had also $28 \%$ less spines in basal dendrites distal to soma $(t=$ 2.877, $\mathrm{df}=9 ; p<0.05)$. Again, in apical dendrites, no significant differences were observed in either proximal or distal segments (Fig. 3B).

\section{Immunohistochemical analysis of Arc protein}

Based on the reduced spine density in hippocampal CA1, the expression of the neuronal activity-related synaptic protein Arc was studied. The region-specific reduction of synaptic spines suggested also a determination of Arc protein levels in three areas of interest within hippocampal CA1: stratum oriens (corresponding to basal dendrites), stratum pyramidale (soma of pyramidal cells), and stratum radiatum (corresponding to apical dendrites). Based on previous reports (Miyashita et al., 2009; Lonergan et al., 2010), we expected a robust Arc protein response at 60-90 min
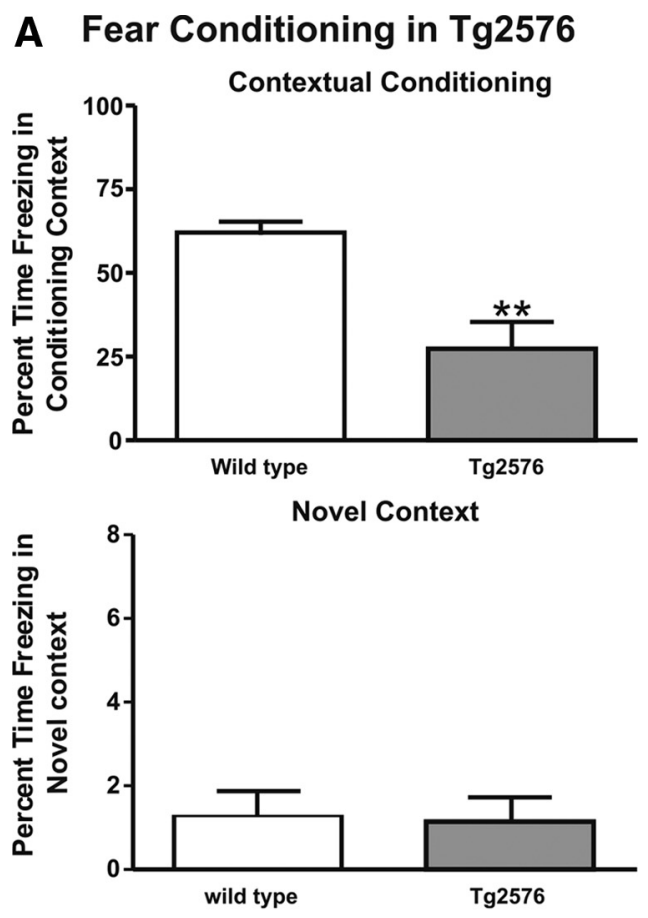

\section{B Water Maze in APP/Lo}

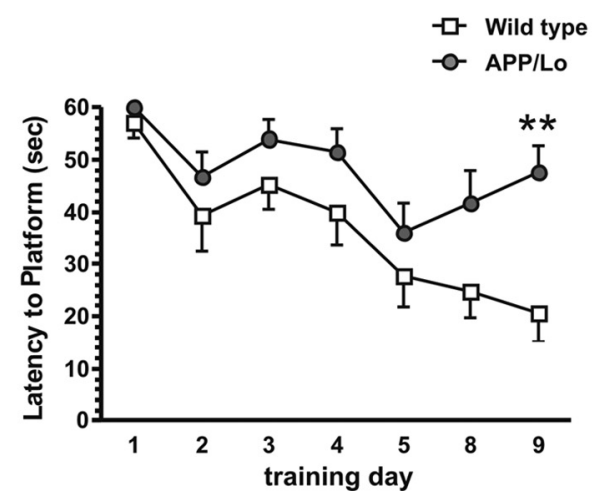

Figure 2. Behavioral deficits (presented as mean + SEM) in APP transgenic mice (gray bars/symbols) and wild-type littermate controls (white bars/symbols). $\boldsymbol{A}, \mathrm{Tg} 2576$ mice showed reduced percentage time freezing when exposed to the context $\left({ }^{* *} p<0.01\right.$ compared with wild-type littermates). $B, A P P / L 0$ mice showed an overall increase in latency to reach the hidden platform $\left({ }^{* *} p<0.01\right)$.

after behavioral testing. Moreover, we have reported previously an elevated number of Arc immunopositive granule cells in dentate gyrus $2 \mathrm{~h}$ after exposure to a novel environment in both wild-type animals and Tg2576 mice (Nolte el al., 2008). To test whether the behavioral test or already the genetic background has an effect on Arc expression in APP transgenic mice, we conducted an experiment in which APP/Lo and wild-type mice were handled for 4 weeks without behavioral test before being killed. We found that the untreated APP/Lo mice presented a significantly higher Arc protein level compared with wild type in stratum oriens, stratum radiatum (both $p<0.001$ ), and stratum pyramidale $(p<0.05)$, indicating that regardless of environmental stimulation, APP transgenic mice present an increased baseline level of Arc protein expression (Fig. 4).

Interestingly, when animals were submitted to behavioral paradigms (i.e., fear conditioning or water maze), the same effect was observed. After the fear conditioning test, Tg2576 mice had a higher density of Arc immunostaining compared 
with wild-type littermates in all hippocampal regions ( $p<0.0001$ ) (Fig. $5 A)$. In APP/Lo mice submitted to the water maze, Arc protein expression was also enhanced compared with wild-type controls, although less dramatically than in Tg2576 mice. The strongest increase compared with the wild-type littermates was found in stratum radiatum $(p<0.0001)$ and stratum oriens $(p<$ $0.01)$, with a smaller but still significant increase in stratum pyramidale $(p<$ 0.05 ) (Fig. 5B). Therefore, the increased Arc protein expression in APP transgenic mice seems to be attributable to a higher baseline level compared with wild-type controls rather than a stronger response to external stimulation.

Quantification of somatostatin-positive cells in Tg2576 mice

Among others, a possible explanation for an increased Arc staining and reduced spine density in stratum oriens of hippocampal CA1 would be the loss of inhibitory interneurons. Therefore, these interneurons were identified and quantified by somatostatin immunohistochemistry. The focus of analysis was laid on areas with considerable presence of SOM-positive cells. This subpopulation of GABAergic interneurons has a limited distribution in CA1 hippocampal region, in which highest density is found in stratum oriens, but none in stratum radiatum and very few in stratum lacunosum-moleculare (Vela et al., 2003; Ramos et al., 2006). Therefore, we included only stratum oriens and stratum lacunosum-moleculare and the dentate gyrus for comparison into analysis (Fig. 1). The Tg2576 mouse strain was used because it has shown the greatest differences in spine and Arc analysis. In these mice, the density of SOM-positive cells was significantly reduced compared with wild-type controls in stratum oriens $(p<0.05)$, but no significant differences were observed in stratum lacunosum-moleculare or in dentate gyrus $(p>0.1)$ (Fig. 6).

\section{Discussion}

In this study, we analyzed several markers of synaptic function in the CA1 hippocampal region known for its vulnerability in $\mathrm{AD}$ patients (Van Hoesen et al., 1990; Arendt et al., 1998, 2001). In APP transgenic mice carrying the Swedish or London mutation of familial Alzheimer's disease, learning and memory impairments are detected at young age, even before amyloid plaque deposition, suggesting that overexpression of APP in the brain induces deficits in hippocampus-dependent functions (Hsiao et al., 1996; Dodart et al., 2000).

The role of $\mathrm{A} \beta$ in the temporal course of $\mathrm{AD}$ and its deposition in the brain in amyloid plaques has been well established (Tanzi Scale bar, $5 \mu \mathrm{m}$.

\section{A Tg2576 mice}
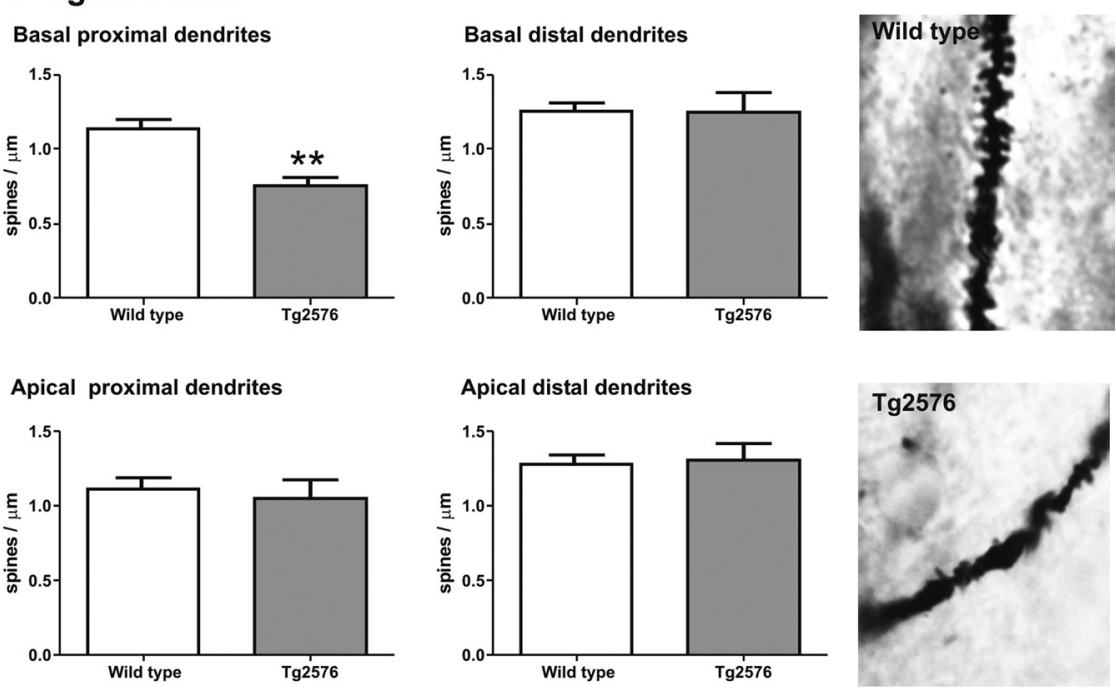

\section{B APP/Lo mice}
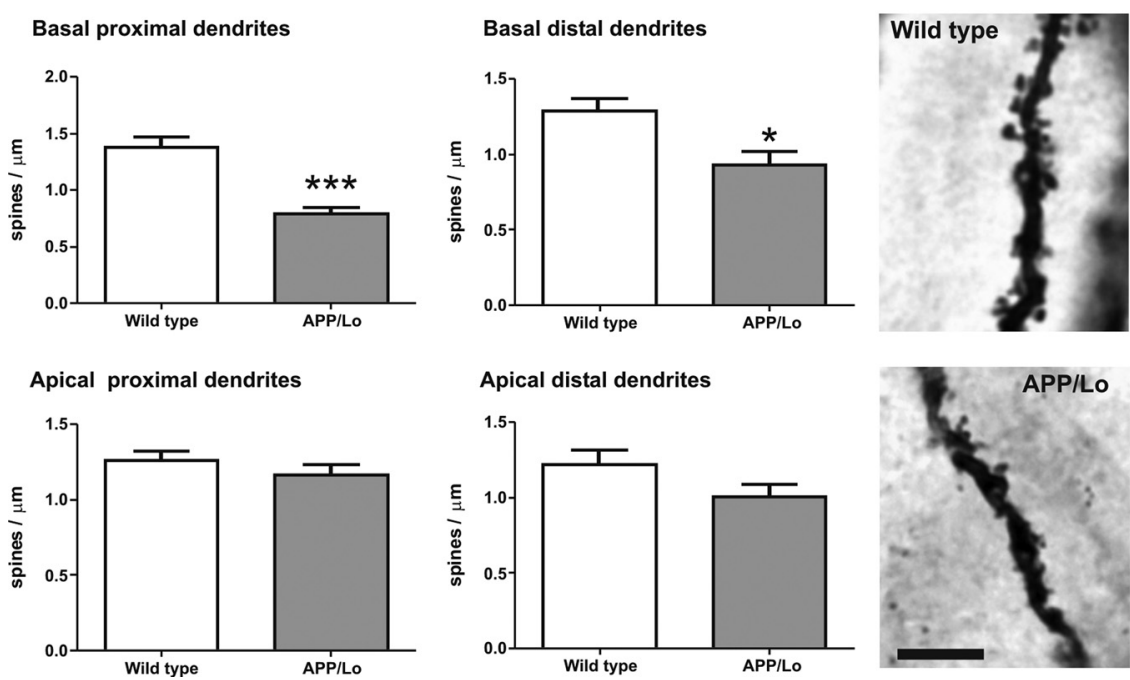

Figure 3. Spine density (mean + SEM) in CA1 region of APP transgenic mice (gray bars) and wild-type littermate controls (white bars). Top panels indicate spine densities in basal dendrites (proximal on left and distal on right, respectively). Bottom panels indicate spine numbers in apical dendrites (proximal on left and distal on right, respectively). Dendritic segments longer than $10 \mu \mathrm{m}$ were analyzed, and only mushroom-like spines were included in the analysis. $A$, Amount of mushroom-like spines was significantly reduced in Tg2576 mice in basal dendrites proximal to soma compared with wild-type littermates $\left({ }^{* *} p<0.01\right)$. No differences were observed in basal dendrites distal to soma or along all apical dendrites. $\boldsymbol{B}$, In APP/Lo mice, mushroom-like spines were reduced in basal dendrites proximal to soma ( ${ }^{* * *} p<0.001$ ) and basal dendrites distal to soma ( ${ }^{*} p<0.05$ ). No differences were observed in apical dendrites. Photomicrographs are representative for the average spine density in the respective groups.

and Bertram, 2005). Small soluble A $\beta$ peptide aggregates (oligomers), which are formed before $\mathrm{A} \beta$ fibrils, have been linked recently to synaptic alterations in several in vitro and in vivo studies (Lambert et al., 1998; Walsh et al., 2002; Ji et al., 2003). To clearly separate effects of oligomeric $\mathrm{A} \beta$ from that of fibrillar deposited $A \beta$, we studied animals at an age when they are still free of plaques but have high levels of $A \beta$ oligomers. When we quantified spine density in pyramidal neurons of CA1 and compared these data with Arc protein expression and SOM interneurons in the same hippocampal region, a complex pattern of changes was observed. A region-specific reduction of synaptic spines in basal dendrites proximal to the soma, accompanied by a reduction of SOM neurons and increased Arc expression, suggests that different inputs cause differential morphological rearrangements in pyrami- 


\section{Arc protein levels in nomal conditions}

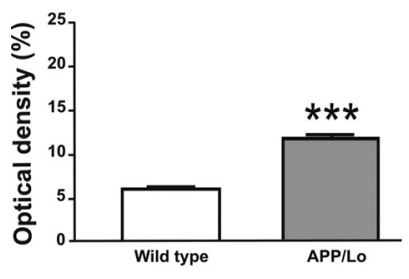

Str. Oriens

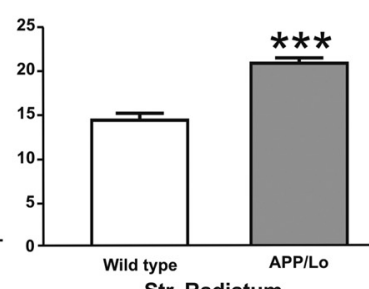

Str. Radiatum

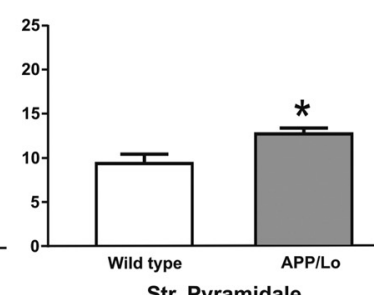

Str. Pyramidale

Figure 4. Arc protein expression levels in APP transgenic mice (gray bars) and wild-type littermate controls (white bars) without behavioral testing. Arc protein expression (mean + SEM optical density) was evaluated in stratum (Str.) oriens, stratum radiatum, and stratum pyramidale of the hippocampal (A1 region (see Fig. 1). APP/Lo mice presented a significantly increased Arc protein level in all analyzed regions compared with wild-type littermates $\left({ }^{*} p<0.05 ;{ }^{* * *} p<0.001\right)$.

\section{A Arc staining in hippocampus}
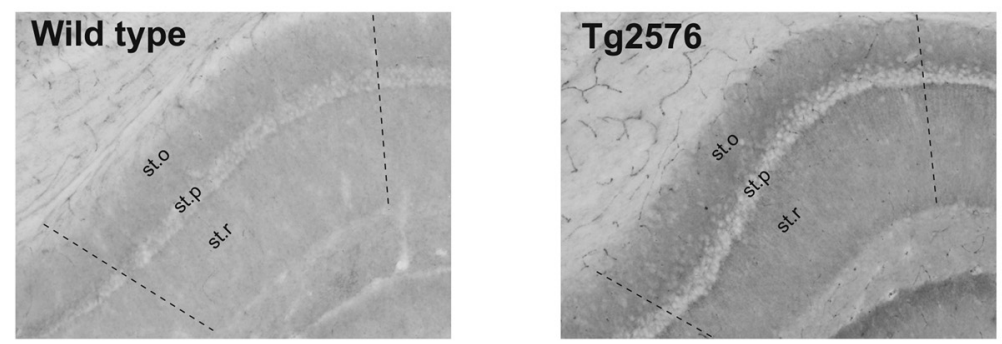

B APP transgenic mice presented increased Arc expression

$\operatorname{Tg} 2576$
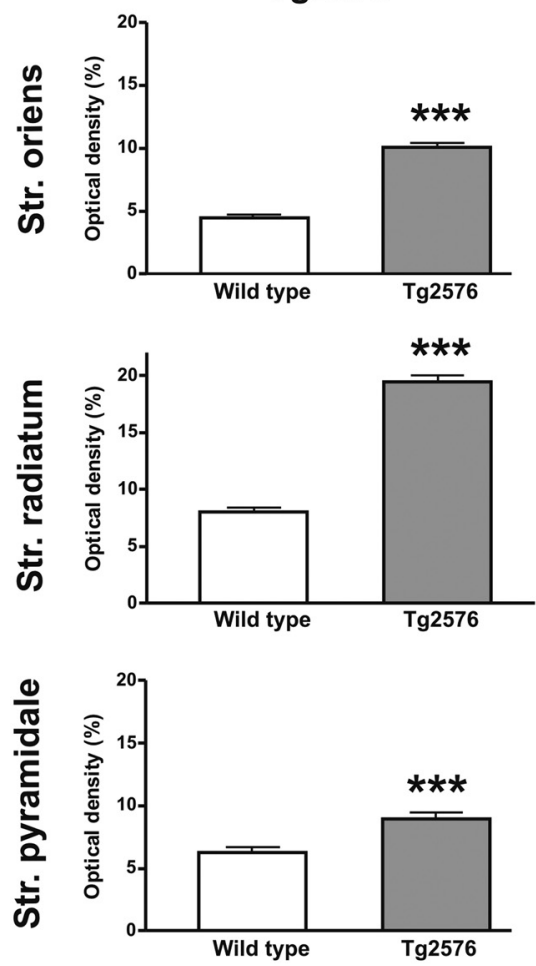

APP/LO
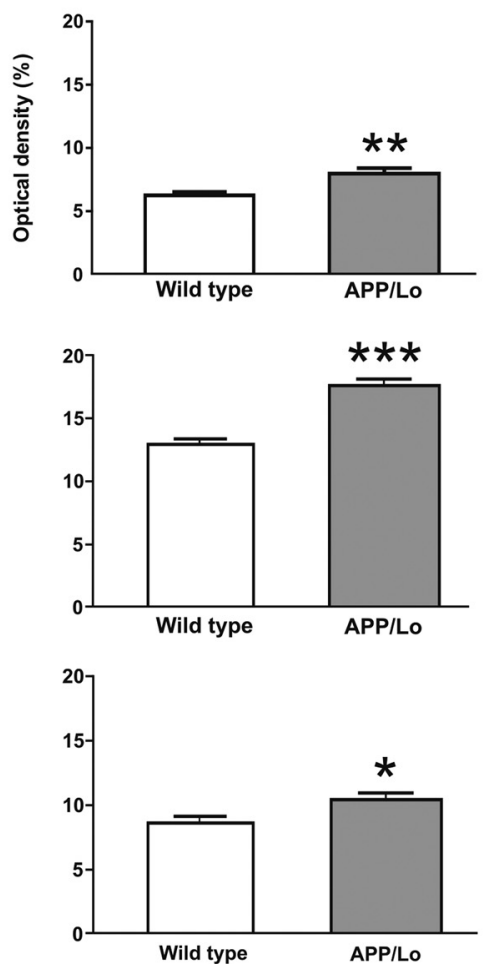

Figure 5. Arc protein expression levels (mean + SEM optical density) in APP transgenic mice (gray bars) and wild-type littermate controls (white bars) after behavioral test. Arc protein expression was evaluated in stratum (Str.) oriens, stratum radiatum, and stratum pyramidale of the hippocampal CA1 region (see Fig. 1). $A$, Representative photomicrographs of Arc staining on a wild-type and $\operatorname{Tg} 2576$ mouse in the hippocampal region (st.o, stratum oriens; st.p, stratum pyramidale; st.r, stratum radiatum). $\boldsymbol{B}, \mathrm{Tg} 2576$ mice killed shortly after fear conditioning test presented significantly increased Arc protein levels in all analyzed regions ( $\left.{ }^{* * *} p<0.0001\right)$ compared with wild-type littermates. APP/Lo mice killed shortly after Morris water maze test also presented strongly increased Arc protein expression in stratum oriens and stratum radiatum $\left({ }^{* *} p<0.0001\right)$, but in stratum pyramidale the difference was less dramatic $\left({ }^{*} p<0.05\right)$.

dal neurons of transgenic mice. These regional morphological rearrangements in spine density in two different transgenic mouse lines suggest a similar soluble $\mathrm{A} \beta$ mediated mechanism of action at least at early stages of the pathology. Moreover, the loss of spines in basal dendrites in Tg2576 and APP/Lo mice correlated with behavioral impairments assessed in the same individuals. Jacobsen et al. (2006) reported a similar correlation of loss of spine number in dentate gyrus and deficit in contextual fear conditioning in 4-month-old Tg2576 mice. There are only few other reports describing spine density changes in the hippocampus of APP transgenic mice. Lanz et al. (2003) compared reduction of synaptic spines at different ages in PDAPP and Tg2576 mice lines. Contrary to our findings, these authors reported decreased number of spines along apical dendrites of pyramidal neurons in CA1 (Lanz et al., 2003). Differences in genetic background and gene inclusions may explain the different results. To date, no other reports have focused in CA1 pyramidal neurons from young $\mathrm{AD}$ transgenic mice models.

Why is the spine density in basal but not apical dendrites of hippocampal CA1 reduced in both APP transgenic mouse lines? There are several possible explanations for such selective loss of spines in young APP transgenic mice. First, soluble $A \beta$ is generated at higher concentration in stratum oriens compared with stratum radiatum and stratum lacunosum-moleculare (Buxbaum et al., 1998; Su and Ni, 1998; Lazarov et al., 2002; Reilly et al., 2003) Second, a general $\mathrm{A} \beta$ overproduction may target specific cell types especially relevant for local network rearrangement, i.e., GABAergic interneurons. On the apical side, CA1 pyramidal neurons receive synaptic input from Schaffer collaterals proximal to the soma and from the entorhinal cortex (via the perforant path) on distal dendrites, whereas the basal dendrites receive most synaptic input from Schaffer collaterals (Spruston and McBain, 2007). Therefore, synaptic input from the same region (i.e., Schaffer collaterals from CA3) impinges on basal and apical proximal dendrites, but spine loss was only detected on basal dendrites. Therefore, axonal innervation from a different region is probably not the reason for the selective loss of spines in CA1 basal dendrites. Selective rearrangement of spine formation or selective elimination of spines on basal and apical dendrites has been reported previously by other authors. For instance, spatial training in a complex environment affects spines in CA1 pyramidal neurons by 
increasing its number on basal dendrites but not on apical dendrites (Moser et al., 1997). Normal aging resulted in decrease of the spine density on basal but not apical dendrites in $\mathrm{C} 57 \mathrm{BL} / 6$ mice, one of the background strains of the APP transgenic mice of this study (van Bohlen et al., 2006). Reelin may play a role in this selectivity because reelin-insufficient heterozygous mice presented a spine reduction on basal dendrites of CA1 pyramidal neurons compared with wild-type littermates, but no significant changes were found in apical dendritic trees (Liu et al., 2001). Chemical treatment can also region-specifically induce spine reductions in CA1 pyramidal neurons of rodents. Neonatal rats exposed repetitively to low doses of paroxon (an organophosphate-type cholinesterase inhibitor) loose dendritic spine selectively in basal dendrites with no changes in apical dendrites of pyramidal neurons in CA1. These changes were accompanied by a reduction in cholinesterase activity in the whole hippocampus (Santos et al., 2004). Because more cholinergic input arrives in the stratum oriens in which the basal dendrites are located, the authors proposed that inhibition of acetylcholine esterase by paroxon leads to accumulation of acetylcholine in this region, thereby increasing the risk of toxic effects in basal versus apical dendrites (Santos et al., 2004). Moreover, these effects could be mediated by muscarinic receptor activation on GABAergic interneurons. Alterations in local GABAergic cells by this toxic compound were also hypothesized (Santos et al., 2004).

Conversely, our Arc data indicate rather a more general synaptic activation in both APP transgenic mice lines compared with their wild-type littermates. Arc is a well known neuronal marker for neuronal activity whose expression is induced during synaptic activity, and its mRNA is rapidly transported to dendritic processes for local translation (Tzingounis et al., 2006; Bramham et al., 2008). In the present study, we first tested whether baseline levels of Arc are different between wild-type and APP transgenic mice and then whether behavioral exposure will affect those levels. In APP/Lo mice that were not submitted to any behavioral test, Arc protein levels were significantly elevated compared with their wild-type littermates. Moreover, when mice were subjected to a hippocampus-dependent memory test shortly before they were killed, there was a similar pattern of enhanced Arc protein expression. Thus, APP transgenic mice seem to have a higher baseline level of Arc protein expression compared with their wild-type controls, indicating general neuronal overexcitation already at baseline condition. Conversely, increased Arc protein levels along all dendritic regions of CA1 (stratum oriens and stratum radiatum) may imply that synaptic spine reduction is not directly correlated with Arc protein levels. It is important to note that our analysis focused on mushroom-type spines, the most permanent spines with a slower turnover rate compared with filopodia (i.e., a lifespan of 7 d) (Yuste and Bonhoeffer, 2004). Therefore, rapid neuronal activation as detected by Arc immunostaining is probably quite distinct from the more permanent change of the number of mushroom-type spines. This leads to the second hypothesis, in which rearrangements in a whole local network might account for the selective spine loss found in basal proximal dendrites of CA1 pyramidal neurons. The most likely candidate for such a local network is that of the inhibitory interneurons. Arai et al. (1994) described significant changes during single theta bursts in CA1 basal and apical dendritic trees, and the basal dendrites undergo greater long-term potentiation than the apical dendrites (Abraham and Wickens, 1991; Leung et al., 1992). These authors suggest that such variations to be related not only to the more complex architecture in basal dendrites versus apical dendrites but also to the distribution of GABAergic interneurons in specific regions of the hippocampus (Jinno and Kosaka, 2000; Cope et al., 2002; Pawelzik et al., 2002). The idea of a local network dysfunction in the hippocampus of $\mathrm{AD}$ patients has been repeatedly suggested (for review, see Burgos-Ramos et al., 2008). Somatostatin, calretinin, and parvalbumin are all markers of GABAergic interneurons in the hippocampus, and they have been used to demonstrate impairment in aged rats by a reduced number of labeled neurons (Vela et al., 2003; Gavilan et al., 2007). Moreover, selective decreases in somatostatin-positive neurons were found in APP $\times$ PS1 mice (an AD model with enhanced pathology) at 6 months of age compared with wild-type mice but only in stratum oriens, corresponding to the region in which basal dendrites are located in our analysis (Ramos et al., 2006). Our analysis of somatostatin-positive cell density in Tg2576 mice, i.e., their selective reduction in stratum oriens, confirms and extends these previous reports.

In summary, we suggest that the observed reduction in dendritic spines on basal proximal dendrites is attributable to a loss of GABAergic interneuron afferents, likely causing glutamate and calcium-mediated overexcitation and local toxicity in stratum oriens. Targeting the basal dendritic region of the hippocampal CA1 and specifically protecting its interneuronal population might be a promising therapeutic strategy to overcome cognitive 
deficits and reduce side effects by more general therapies in $\mathrm{AD}$ patients.

\section{References}

Abraham WC, Wickens JR (1991) Heterosynaptic long-term depression is facilitated by blockade of inhibition in area CA1 of the hippocampus. Brain Res 546:336-340.

Arai A, Black J, Lynch G (1994) Origins of the variations in long-term potentiation between synapses in the basal versus apical dendrites of hippocampal neurons. Hippocampus 4:1-9.

Arendt T (2001) Disturbance of neuronal plasticity is a critical pathogenetic event in Alzheimer's disease. Int J Dev Neurosci 19:231-245.

Arendt T, Brückner MK, Gertz HJ, Marcova L (1998) Cortical distribution of neurofibrillary tangles in Alzheimer's disease matches the pattern of neurons that retain their capacity of plastic remodelling in the adult brain. Neuroscience 83:991-1002.

Bonhoeffer T, Yuste R (2002) Spine motility. Phenomenology, mechanisms, and function. Neuron 35:1019-1027.

Bramham CR, Worley PF, Moore MJ, Guzowski JF (2008) The immediate early gene Arc/Arg3.1: regulation, mechanisms, and function. J Neurosci 28:11760-11767.

Burgos-Ramos E, Hervás-Aguilar A, Aguado-Llera D, Puebla-Jiménez L, Hernández-Pinto AM, Barrios V, Arilla-Ferreiro E (2008) Somatostatin and Alzheimer's disease. Mol Cell Endocrinol 286:104-111.

Buxbaum JD, Thinakaran G, Koliatsos V, O'Callahan J, Slunt HH, Price DL, Sisodia SS (1998) Alzheimer amyloid protein precursor in the rat hippocampus: transport and processing through the perforant path. J Neurosci 18:9629-9637.

Calabrese B, Shaked GM, Tabarean IV, Braga J, Koo EH, Halpain S (2007) Rapid, concurrent alterations in pre- and postsynaptic structure induced by naturally secreted amyloid-beta protein. Mol Cell Neurosci 35:183-193.

Cheng HW, Rafols JA, Goshgarian HG, Anavi Y, Tong J, McNeill TH (1997) Differential spine loss and regrowth of striatal neurons following multiple forms of deafferentation: a Golgi study. Exp Neurol 147:287-298.

Cope DW, Maccaferri G, Márton LF, Roberts JD, Cobden PM, Somogyi P (2002) Cholecystokinin-immunopositive basket and Schaffer collateralassociated interneurones target different domains of pyramidal cells in the CAl area of the rat hippocampus. Neuroscience 109:63-80.

DeKosky ST, Scheff SW (1990) Synapse loss in frontal cortex biopsies in Alzheimer's disease: correlation with cognitive severity. Ann Neurol 27:457-464.

Dodart JC, Mathis C, Saura J, Bales KR, Paul SM, Ungerer A (2000) Neuroanatomical abnormalities in behaviorally characterized $\mathrm{APP}(\mathrm{V} 717 \mathrm{~F})$ transgenic mice. Neurobiol Dis 7:71-85.

Gavilán MP, Revilla E, Pintado C, Castaño A, Vizuete ML, Moreno-González I, Baglietto-Vargas D, Sánchez-Varo R, Vitorica J, Gutiérrez A, Ruano D (2007) Molecular and cellular characterization of the age-related neuroinflammatory processes occurring in normal rat hippocampus: potential relation with the loss of somatostatin GABAergic neurons. J Neurochem 103:984-996.

Gibb R, Kolb B (1998) A method for vibratome sectioning of Golgi-Cox stained whole rat brain. J Neurosci Methods 79:1-4.

Gould E, Westlind-Danielsson A, Frankfurt M, McEwen BS (1990) Sex differences and thyroid hormone sensitivity of hippocampal pyramidal cells. J Neurosci 10:996-1003.

Hsiao K, Chapman P, Nilsen S, Eckman C, Harigaya Y, Younkin S, Yang F, Cole G (1996) Correlative memory deficits, Abeta elevation, and amyloid plaques in transgenic mice. Science 274:99-102.

Jacobsen JS, Wu CC, Redwine JM, Comery TA, Arias R, Bowlby M, Martone R, Morrison JH, Pangalos MN, Reinhart PH, Bloom FE (2006) Earlyonset behavioral and synaptic deficits in a mouse model of Alzheimer's disease. Proc Natl Acad Sci U S A 103:5161-5166.

Ji Y, Gong Y, Gan W, Beach T, Holtzman DM, Wisniewski T (2003) Apolipoprotein $\mathrm{E}$ isoform-specific regulation of dendritic spine morphology in apolipoprotein E transgenic mice and Alzheimer's disease patients. Neuroscience 122:305-315

Jinno S, Kosaka T (2000) Colocalization of parvalbumin and somatostatinlike immunoreactivity in the mouse hippocampus: quantitative analysis with optical dissector. J Comp Neurol 428:377-388.

Kokubo H, Kayed R, Glabe CG, Yamaguchi H (2005) Soluble Abeta oligomers ultrastructurally localize to cell processes and might be related to synaptic dysfunction in Alzheimer's disease brain. Brain Res 1031:222-228

Lacor PN, Buniel MC, Furlow PW, Clemente AS, Velasco PT, Wood M, Viola KL, Klein WL (2007) A $\beta$ oligomer-induced aberrations in synapse composition, shape, and density provide a molecular basis for loss of connectivity in Alzheimer's disease. J Neurosci 27:796-807.

Lambert MP, Barlow AK, Chromy BA, Edwards C, Freed R, Liosatos M, Morgan TE, Rozovsky I, Trommer B, Viola KL, Wals P, Zhang C, Finch CE, Krafft GA, Klein WL (1998) Diffusible, nonfibrillar ligands derived from Abeta1-42 are potent central nervous system neurotoxins. Proc Natl Acad Sci U S A 95:6448-6453.

Lanz TA, Carter DB, Merchant KM (2003) Dendritic spine loss in the hippocampus of young PDAPP and Tg2576 mice and its prevention by the ApoE2 genotype. Neurobiol Dis 13:246-253.

Lazarov O, Lee M, Peterson DA, Sisodia SS (2002) Evidence that synaptically released $\beta$-amyloid accumulates as extracellular deposits in the hippocampus of transgenic mice. J Neurosci 22:9785-9793.

Leung LS, Shen B, Kaibara T (1992) Long-term potentiation induced by patterned stimulation of the commissural pathway to hippocampal CA1 region in freely moving rats. Neuroscience 48:63-74.

Lippa CF, Hamos JE, Pulaski-Salo D, DeGennaro LJ, Drachman DA (1992) Alzheimer's disease and aging: effects on perforant pathway perikarya and synapses. Neurobiol Aging 13:405-411.

Liu WS, Pesold C, Rodriguez MA, Carboni G, Auta J, Lacor P, Larson J, Condie BG, Guidotti A, Costa E (2001) Down-regulation of dendritic spine and glutamic acid decarboxylase 67 expressions in the reelin haploinsufficient heterozygous reeler mouse. Proc Natl Acad Sci USA 98:3477-3482.

Lonergan ME, Gafford GM, Jarome TJ, Helmstetter FJ (2010) Timedependent expression of Arc and Zif268 after acquisition of fear conditioning. Neural Plast 2010:139891.

Masliah E, Terry RD, Alford M, DeTeresa R, Hansen LA (1991) Cortical and subcortical patterns of synaptophysinlike immunoreactivity in Alzheimer's disease. Am J Pathol 138:235-246.

McLean CA, Cherny RA, Fraser FW, Fuller SJ, Smith MJ, Beyreuther K, Bush AI, Masters CL (1999) Soluble pool of Abeta amyloid as a determinant of severity of neurodegeneration in Alzheimer's disease. Ann Neurol 46:860-866.

Miyashita T, Kubik S, Haghighi N, Steward O, Guzowski JF (2009) Rapid activation of plasticity-associated gene transcription in hippocampal neurons provides a mechanism for encoding of one-trial experience. J Neurosci 29:898-906.

Moechars D, Dewachter I, Lorent K, Reversé D, Baekelandt V, Naidu A, Tesseur I, Spittaels K, Haute CV, Checler F, Godaux E, Cordell B, Van Leuven F (1999) Early phenotypic changes in transgenic mice that overexpress different mutants of amyloid precursor protein in brain. J Biol Chem 274:6483-6492.

Moser MB, Trommald M, Egeland T, Andersen P (1997) Spatial training in a complex environment and isolation alter the spine distribution differently in rat CA1 pyramidal cells. J Comp Neurol 380:373-381.

Nolte MW, Jongen-Rêlo AL, Meyer AH, Gross G, Schoemaker H, Ebert U (2008) Activity- and age-dependent alterations of Arc expression in the brain of Tg2576 mice. Soc Neurosci Abstr 34:441.1.

Parnavelas JG, Lynch G, Brecha N, Cotman CW, Globus A (1974) Spine loss an regrowth in hippocampus following deafferentation. Nature 248:71-73.

Pawelzik H, Hughes DI, Thomson AM (2002) Physiological and morphological diversity of immunocytochemically defined parvalbumin- and cholecystokinin-positive interneurones in CA1 of the adult rat hippocampus. J Comp Neurol 443:346-367.

Paxinos G, Franklin KB (2001) The mouse brain in stereotaxic coordinates, Ed 2. Hong Kong: Academic.

Ramos B, Baglietto-Vargas D, del Rio JC, Moreno-Gonzalez I, Santa-Maria C, Jimenez S, Caballero C, Lopez-Tellez JF, Khan ZU, Ruano D, Gutierrez A, Vitorica J (2006) Early neuropathology of somatostatin/NPY GABAergic cells in the hippocampus of a PS1xAPP transgenic model of Alzheimer's disease. Neurobiol Aging 27:1658-1672.

Reilly JF, Games D, Rydel RE, Freedman S, Schenk D, Young WG, Morrison JH, Bloom FE (2003) Amyloid deposition in the hippocampus and entorhinal cortex: quantitative analysis of a transgenic mouse model. Proc Natl Acad Sci U S A 100:4837-4842.

Santos HR, Cintra WM, Aracava Y, Maciel CM, Castro NG, Albuquerque EX 
(2004) Spine density and dendritic branching pattern of hippocampal CA1 pyramidal neurons in neonatal rats chronically exposed to the organophosphate paraoxon. Neurotoxicology 25:481-494.

Shankar GM, Bloodgood BL, Townsend M, Walsh DM, Selkoe DJ, Sabatini BL (2007) Natural oligomers of the Alzheimer amyloid- $\beta$ protein induce reversible synapse loss by modulating an NMDA-type glutamate receptor-dependent signaling pathway. J Neurosci 27:2866-2875.

Sprusston N, McBain C (2007) Structure and functional properties of hippocampal neurons. In: The hippocampus book (Andersen P, Morris R, Amaral D, Bliss T, O’Keefe J, eds), pp 133-188. New York: Oxford UP.

Su Y, Ni B (1998) Selective deposition of amyloid-beta protein in the entorhinal dentate projection of a transgenic mouse model of Alzheimer's disease. J Neurosci Res 53:177-186.

Sze CI, Troncoso JC, Kawas C, Mouton P, Price DL, Martin LJ (1997) Loss of the presynaptic vesicle protein synaptophysin in hippocampus correlates with cognitive decline in Alzheimer disease. J Neuropathol Exp Neurol 56:933-944.

Takahashi RH, Almeida CG, Kearney PF, Yu F, Lin MT, Milner TA, Gouras GK (2004) Oligomerization of Alzheimer's $\beta$-amyloid within processes and synapses of cultured neurons and brain. J Neurosci 24:3592-3599.

Tanghe A, Termont A, Merchiers P, Schilling S, Demuth H, Scrocchi L, Van Leuven F, Griffioen G, Van Dooren T (2010) Pathological hallmarks, clinical parallels and value for drug testing in Alzheimer's disease of the APP[V717I] London transgenic mouse model. Int J Alzheimers Dis pii:417314.
Tanzi RE, Bertram L (2005) Twenty years of the Alzheimer's disease amyloid hypothesis: a genetic perspective. Cell 120:545-555.

Terry RD (1998) The cytoskeleton in Alzheimer disease. J Neural Transm Suppl 53:141-145.

Terry RD, Masliah E, Salmon DP, Butters N, DeTeresa R, Hill R, Hansen LA, Katzman R (1991) Physical basis of cognitive alterations in Alzheimer's disease: synapse loss is the major correlate of cognitive impairment. Ann Neurol 30:572-580.

Tzingounis AV, Nicoll RA (2006) Arc/Arg3.1: linking gene expression to synaptic plasticity and memory. Neuron 52:403-407.

Van Hoesen GW, Hyman BT (1990) Hippocampal formation: anatomy and the patterns of pathology in Alzheimer's disease. Prog Brain Res 83:445-457.

Vela J, Gutierrez A, Vitorica J, Ruano D (2003) Rat hippocampal GABAergic molecular markers are differentially affected by ageing. J Neurochem 85:368-377.

von Bohlen und Halbach O, Zacher C, Gass P, Unsicker K (2006) Agerelated alterations in hippocampal spines and deficiencies in spatial memory in mice. J Neurosci Res 83:525-531.

Walsh DM, Klyubin I, Fadeeva JV, Cullen WK, Anwyl R, Wolfe MS, Rowan MJ, Selkoe DJ (2002) Naturally secreted oligomers of amyloid beta protein potently inhibit hippocampal long-term potentiation in vivo. Nature 416:535-539.

Yuste R, Bonhoeffer T (2004) Genesis of dendritic spines: insights from ultrastructural and imaging studies. Nat Rev Neurosci 5:24-34. 